\title{
Os rastros de memória e a dinâmica da criação na teledramaturgia brasileira ${ }^{1}$
}

\section{Nísia Martins do Rosário}

Doutora; Universidade Federal do Rio Grande do Sul nisiamartins@gmail.com

\section{Adriana Pierre Coca}

Doutoranda; Universidade Federal do Rio Grande do Sul pierrecoca@hotmail.com

\section{Resumo}

$\mathrm{O}$ artigo discorre sobre a memória na teledramaturgia. Nosso principal aporte teórico-metodológico é a Semiótica da Cultura na confluência com a narrativa de ficção. Partimos de um levantamento de técnicas narrativas enraizadas nas matrizes clássicas de escrever histórias ficcionais para TV, principalmente as características herdadas do melodrama e do folhetim. Essa trajetória nos ajuda a entender o papel da memória dos sistemas culturais na composição da ficção seriada de televisão, sobretudo da telenovela, considerando a cultura como uma memória coletiva por incorporar a historicidade dos sistemas de signos. Conclui-se que a ficção seriada televisual contemporânea é um texto que traz à tona a reconfiguração nos modos de se produzir e narrar próprios da era da comunicação digital, constituindo-se na atualização de processos graduais e explosivos. Ainda assim, essas mesmas narrativas se mantêm ancoradas na linguagem clássica.

\section{Palavras-chave}

Teledramaturgia. Fiç̧ão seriada. Memória. Semiótica da cultura. criação.

\footnotetext{
${ }^{1}$ Uma versão desse texto foi apresentada no 10. Encontro Nacional de História da Mídia realizado de 3 a 5 de junho de 2015, na Universidade Federal do Rio Grande do Sul, em Porto Alegre/RS.
} 


\section{Introdução: o contexto do objeto}

Sabemos que a televisão tem uma função social de destaque. Na América Latina, é o meio de comunicação de maior acessibilidade em muitos países, presente em 96\% dos lares brasileiros, 97\% no Chile e 99\% no Peru, segundo informações do Ibope Media². Nesse contexto, a ficção seriada ocupa 19\% da grade de programação das principais emissoras abertas no Brasil33, ou seja, as narrativas ficcionais televisuais são um meio de expressão e significação importante na cultura brasileira, mesmo diante da velocidade com que as mídias digitais remodelam os modos de se comunicar.

Logo, é preciso atenção às mudanças ocorridas na teledramaturgia e às possibilidades provocadas pelas aceleradas reconfigurações da era digital. Transformações essas que estão conectadas ao arcabouço histórico que constitui a teledramaturgia, a partir das experiências anteriores de contar histórias, de escrever ficção. 0 estudo da teledramaturgia, num viés diacrônico, permite uma reflexão sobre a configuração que vem assumindo sua linguagem na relação com os sistemas culturais, a memória e a comunicação midiática.

Partimos do pressuposto de que a matriz tradicional de contar histórias passa por um movimento contínuo de atualização que é próprio da dinamicidade da comunicação e da cultura. A compreensão de alguns dos aspectos desse processo auxilia a criar um panorama da constituição da linguagem específica da teledramaturgia brasileira, do modo como ela se organiza e produz narrativas.

O questionamento que se impôs foi: qual papel a memória (que estrutura tais histórias) assume numa narrativa ficcional na televisão? Para refletir sobre isso, adotamos como aporte teórico-metodológico a semiótica da cultura (SC), alicerçando a discussão numa perspectiva diacrônica que nos permite recuperar elementos da herança melodramática da teledramaturgia, bem como suas marcas folhetinescas, as configurações assumidas por sua linguagem, os processos de descontinuidade e imprevisibilidade que a atravessam.

Antes de adentrar nesses aspectos, contudo, é importante relembrar o modo como a SC entende o conceito de cultura. Ela é compreendida por Lotman (2000) como uma memória coletiva, que se organiza a partir da combinação de vários sistemas de signos, cada um com codificação própria, que se estabelece na relação entre esses sistemas. Nessa memória

\footnotetext{
2 Informações disponíveis em: TV aberta segue como meio de maior penetração na américa latina (2013).

${ }^{3}$ No Brasil, são seis redes nacionais de televisão aberta (Globo, Record, SBT, Bandeirantes e Rede TV, privadas, e a TV Brasil, pública). Com exceção da Rede TV, todas as outras produziram e exibiram programas de ficção em 2012, segundo dados do Anuário Obitel, Observatório Ibero-americano de Ficção Televisiva (LOPES; OROZCO GÓMEZ, 2013).
} 
coletiva, alguns textos ${ }^{4}$ podem se conservar e se atualizar sob alguma invariante de sentido, permitindo que a memória informativa seja assegurada pela presença de alguns textos constantes e pela unidade dos códigos (ou por sua invariância), mas também pelo caráter ininterrupto de sua transformação. Existe também a memória criadora, responsável pela edificação de novos textos na cultura e própria da arte, pois está em potência e pode se atualizar nos textos, como no caso da criação de diversos formatos e narrativas para contar histórias de ficção no audiovisual.

Cada cultura define o paradigma do que deve recordar (isto é, conservar) e o que deve esquecer. 0 que se deve esquecer é apagado da memória coletiva, é como se deixasse de existir. Mas com o passar do tempo, o sistema de códigos da cultura também muda o paradigma da memória e o que deve ser esquecido. (LOTMAN, 2000, p. 160, tradução nossa).

Assim, memória e cultura estão correlacionadas, sendo que a primeira se compõe pela conjugação de simultaneidades e de sucessões e, nesse percurso, segundo Lotman (1996), assume um caráter pancrônico. Essa correlação entre diacronia e sincronia permite entender que:

0 processo de envelhecimento dos diversos métodos de geração de sentidos, constantemente ativos, é compensado, por um lado, pela introdução e o uso de novas estruturas geradoras de sentido, antes proibidas; e, por outro, pelo rejuvenescimento das velhas e esquecidas. (LOTMAN, 2000, p. 36).

Na organização deste artigo entendemos que, num primeiro momento, é importante nos atermos a considerações sobre o eixo diacrônico da teledramaturgia, as sucessões retidas pela memória coletiva, considerando aspectos que constituem o território da cultura. Para tanto, abordamos dois eixos que se mostram mais robustos na constituição do sistema da teledramaturgia e da sua linguagem: o melodrama e o folhetim. Temos consciência, não obstante, de que eles não são os únicos e nem dão conta da diacronicidade da ficção seriada.

\footnotetext{
${ }^{4} \mathrm{O}$ conceito de texto para a SC se configura pelo princípio da trama, já que, ao recorrer à etimologia da palavra, o autor observa que o termo inclui a ideia de entramar-se nos fios do tecido. "0 texto não se apresenta como a realização de uma mensagem em uma só linguagem, mas como um complexo dispositivo que se compõe de vários códigos, capaz de transformar as mensagens recebidas e gerar novas mensagens [...]." (LOTMAN, 2003, doc. eletrônico). 0 texto é um gerador de sentidos que inclui tanto a dimensão do emissor quanto a do receptor, bem como elementos casuais e, nessa via, abriga a interação de múltiplos sistemas semióticos, bem como a contradição e a indefinição de sentidos. É um conceito que está em correlação com o espaço semiótico que se consolida na semiosfera.
} 


\section{A herança melodramática ${ }^{5}$}

Na perspectiva da SC, é possível dizer que parte de todas as histórias de ficção está conectada à teledramaturgia, mas sua abrangência conceitual engloba apenas as histórias de ficção escritas para a televisão. Sem dúvida, a teledramaturgia agrada muita gente, atinge um público vasto e está acessível facilmente. Os pesquisadores Martín-Barbero e Rey justificam o poder de tanta repercussão e indicam os riscos:

No que diz respeito à televisão, é certo que do México à Patagônia argentina, essa mídia convoca hoje as pessoas, como nenhuma outra, mas o rosto de nossos países que aparece na televisão é um rosto contrafeito e deformado pela trama dos interesses econômicos e políticos, que sustentam e amoldam essa mídia. Ainda assim, a televisão constitui um âmbito decisivo do reconhecimento sociocultural, do desfazer-se do refazer-se das identidades coletivas, tanto as do povo como as de grupos. (2001, p. 114).

A citação acima suscita muitos questionamentos. Entre eles está a perspectiva de que a televisão possibilita o reconhecimento sociocultural dos povos. Assim sendo, a teledramaturgia se constitui como o "drama do reconhecimento" (MARTÍN-BARBERO, 2009, p. 306), um drama que tem como base para sua construção o gênero melodramático. MartínBarbero, em seu texto referencial Dos meios às mediações (2009), ratifica: nenhum outro gênero agrada tanto como o melodrama na América Latina. "É como se estivesse nele o modo de expressão mais aberto ao modo de viver e sentir da nossa gente." (MARTÍN-BARBERO, 2009 , p. 305). Afirmação que remete a outro estudioso do assunto, Peter Brooks, na obra The melodramatic imagination (1995), onde afirma que, mais que um gênero, o melodrama se configura como um modo de vida, o modo melodramático, uma espécie de consciência fundamental na contemporaneidade.

Pode-se perceber que os elementos como o drama do reconhecimento, o modo de vida, a convocação feita pelas histórias, as tramas deformadas pelos interesses econômicos e políticos - entre outros que têm herança do melodrama - se atualizam em formas e velocidades diferentes na televisão dos países da América Latina. Nesse sentido, é preciso considerar, conforme Lotman (2000, p.153), que são evidentes as diferenças de forma e de velocidade na dinâmica dos sistemas culturais e, consequentemente, na história de seus componentes. Ou seja, "[...] as rodas da cultura rodam em diferentes velocidades".

Os aspectos semióticos da cultura se desenvolvem melhor segundo leis que recordam as leis da memória, sendo que o que passou não é aniquilado nem passa a inexistência, mas sim, sofrendo uma seleção e uma complexa

${ }^{5}$ Parte das reflexões referentes ao melodrama e ao folhetim já foram realizadas em Coca (2014). 
codificação, passa a ser conservado para, em determinadas condições, voltar a se manifestar. (LOTMAN, 2000, p. 153, tradução nossa).

As reflexões de Lotman nos ajudam a compreender que cada sistema cultural tem suas especificidades e que há relevância em se fazer um rastreamento de elementos que vão se manifestando no eixo diacrônico, deixando suas marcas de diversas maneiras na memória coletiva (na cultura). Por isso, recorre-se ao melodrama (e mais adiante ao folhetim).

A noção mais original de melodrama está associada às emoções acentuadas, no entanto, o gênero configura muito mais que apenas um "[...] drama exagerado e lacrimejante [...]" (THOMASSEAU, 2005, p. 9), como já apontaram os autores acima. Historicamente, o melodrama surge no teatro popular, que se desvia dos critérios clássicos de contar histórias no palco e utiliza a música como apoio para os efeitos dramáticos. E embora a origem da palavra tenha surgido no século XVII, na Itália, para designar "[...] um drama inteiramente cantado [...]" (THOMASSEAU, 2005, p. 16), foi na França, após revolução de 1789, que o gênero se desenvolveu; a relação que se faz é que os tempos de crise daquele momento histórico impulsionaram consideravelmente o gosto pelo teatro (THOMASSEAU, 2005). Assim sendo, a gênese do melodrama está associada à ópera italiana, especificamente à opereta, que é um tipo de ópera popular, mais leve; no entanto, o gênero só se acentua no século seguinte, em um período histórico conturbado, no qual a Europa vivenciava profunda crise.

No cenário que antecedeu a Revolução, os salões de arte eram acessíveis às elites, e as expressões artísticas do povo resgatavam nas ruas as narrativas orais, por meio dos contadores de histórias, do teatro de saltimbancos, dos espetáculos de mímicas e das histórias de amor contadas por atores mascarados. Essas manifestações encaminharam o surgimento do vaudeville, no século XVIII, na França, espetáculo que despontou como um teatro popular associado às comédias, com personagens ingênuos. Mais tarde, os vaudevilles fizeram muito sucesso nos Estados Unidos, também oferecendo uma espécie de teatro de variedades com acrobatas, ilusionistas, músicos e animais treinados. São os vaudevilles que passam a designar todo o tipo de teatro, menos aquele que pertencia à companhia nacional francesa, a Comédie Française (BULHÕES, 2009).

Martín-Barbero lembra que, entre o final do século XVII e o início do século XIX, “[...] disposições governamentais 'destinadas a combater o alvoroço' proíbem na Inglaterra e na França a existência de teatros populares nas cidades [...]." (2009, p. 163). A justificativa da 
proibição era: não corromper o verdadeiro teatro. A proibição em Paris foi suspensa em $1806^{6}$.

Esses momentos históricos que marcaram a diacronicidade do melodrama se conectam à afirmação de Lotman (2000) de que os sistemas dos códigos culturais vão definindo seus paradigmas sobre o que deve ser conservado e o que deve ser esquecido, contudo a passagem do tempo mostra que os padrões podem mudar e o que está esquecido pode ser incorporado novamente ao sistema. Por outras palavras, o melodrama foi se atualizando constantemente e, nesse processo, conservou muitas de suas características significativas e, por vezes, reincorporou outras tantas.

Ele é o gênero que revolucionou a criação das narrativas de ficção. De maneira genérica, pode-se dizer que os textos melodramáticos se estruturam sobre o paradigma da luta entre o bem e o mal absolutos, que é repleta de obstáculos, mas, no final, os vilões são castigados e os virtuosos recompensados. Nessa construção há, ainda, o alívio cômico e o tributo ao inesperado, como os acidentes. É dessa forma que as histórias melodramáticas abrem espaço para as emoções e para a imaginação do público (THOMASSEAU, 2005).

Deve-se levar em conta que, na época de sua criação, o público que passa a ter acesso às encenações construídas a partir dos melodramas ainda está sensibilizado pelas experiências vividas na revolução e se reconhece no palco; é nessa relação que o melodrama se converte no "espelho de uma consciência coletiva" (MARTÍN-BARBERO, 2009, p. 164).

No início do século XIX, o melodrama já assumia um estatuto ambíguo, era amado pelas plateias e criticado severamente pelos críticos e historiadores (THOMASSEAU, 2005). Em contraponto ao teatro das elites, no melodrama a encenação era privilegiada. Na França, os críticos consideravam um absurdo a ação dramática ter mais destaque que a palavra, o texto. 0 espetáculo visual, os efeitos sonoros, as pantominas e a dança ganhavam espaço nos palcos, e a música servia para "[...] marcar os momentos solenes ou cômicos, para caracterizar o traidor e preparar a entrada da vítima, para ampliar a tensão ou relaxá-la, além das canções e da música dos balés [...]." (MARTÍN-BARBERO, 2009, p. 166). Com essas especificidades, o melodrama conquistou também as plateias internacionais, sendo levado para Inglaterra, Alemanha e Estados Unidos, tornando-se assim um dos mais bem-sucedidos gêneros do teatro do século XIX.

${ }^{6}$ Nesse ínterim, surge a obra de origem do melodrama, reconhecida por vários autores no contexto europeu como sendo Coelina ou a Filha do Mistério, escrita por René-Charles Guilbert de Pixerécourt em 1800. 
Com base nesse contexto, já se compreende o porquê de o melodrama deixar suas marcas nas narrativas ficcionais dos séculos vindouros. As matrizes do melodrama vão para o cinema, para as radionovelas e, por consequência, chegam também à televisão, sendo a telenovela sua cristalização mais evidente no Brasil. A música e os efeitos sonoros nas narrativas ficcionais, por exemplo, ganham seu resplendor nas radionovelas. Já os efeitos óticos, vindos das trupes de teatro que utilizavam fantasmagorias e sombras chinesas, foram absorvidos pelo cinema.

Quatro personagens alicerçam as histórias melodramáticas: o traidor ou perseguidor ou agressor; a vítima, que em geral é o herói ou a heroína; o protetor ou justiceiro; e o bobo. Outra característica importante é a ênfase na atuação, que irá permear as encenações que se seguem com as produções audiovisuais. 0 gesto é um aspecto de forte codificação na cultura popular, antes mesmo do advento dos espetáculos melodramáticos, quando o teatro popular era combatido pela burguesia. Isso porque, desde 1680, os diálogos não podiam existir na arte feita nas ruas; como consequência, as expressões e gestos dos atores ganhavam destaque, também eram utilizados cartazes e faixas que correspondiam às falas, às canções. Sendo assim, o teatro que surge com o melodrama tem necessidade, quase uma emergência, de se expressar/falar e faz isso por meio do excesso de gestos e pela ênfase nos sentimentos para “[...] uma cultura que não pôde ser 'educada' pelo padrão burguês [...]” (MARTíNBARBERO, 2009, p. 167). Pode-se perceber que esses aspectos têm sofrido algumas atualizações na linguagem da ficção seriada brasileira contemporânea. As categorias de personagens persistem ainda hoje em muitas das tramas de ficção seriada televisiva, mas seus traços nem sempre são tão marcados, nem representados de forma tão simplificada. Os gestos que assinalavam as telenovelas brasileiras dos primeiros tempos, e mesmo as produções mexicanas, atualmente não são tão enfatizados na dramatização.

Importante reforçar que, nessa condição, o gênero se torna uma vertente popular, tanto que Martín-Barbero (2009) afirma que o melodrama se coloca no "[...] vértice mesmo do processo que leva do popular ao massivo: lugar de chegada de uma memória narrativa e gestual e lugar de emergência de uma cena de massa [...]." (MARTÍN-BARBERO, 2009, p. 164). Nos dias de hoje ainda se pode perceber esse traço marcante que vai do popular ao massivo nas telenovelas: apreciadas pelo público médio da televisão, criticadas por uma camada da intelectualidade e aparentemente menosprezadas pelas elites.

Nesse sentido, Martín-Barbero observa que alguns estudiosos rechaçam o gênero melodramático, denunciando que a moral é o que fica dos espetáculos apresentados, conver- 
tendo-se numa forma de propaganda de determinados valores. Contudo, o autor discorda e completa: “[...] o melodrama não se esgota aí, tem outra face, outro espaço de desdobramento e outra significação pela qual se liga com aquela matriz cultural que vínhamos rastreando [...]." (MARTÍN-BARBERO, 2009, p. 171). Ele se refere ao modo de simbolizar o social vivido de maneira metafórica por meio da retórica do excesso, que exige do público uma resposta, seja com risadas, lágrimas ou temores.

Os argumentos desenvolvidos até então dão indícios para responder à pergunta que implicitamente norteou a primeira inquietação desse tópico: Por que a teledramaturgia agrada tanta gente? Porque a ficção seriada carrega traços do melodrama, que ao persistirem como padrão nos sistemas de narrativa televisiva, fazem conexão com a memória coletiva e com o drama do reconhecimento: tem forte carga de subjetividade, opera sobre as emoções e, assim, constrói intensa capacidade de conexão com o público; cria uma (estereotipada) identidade coletiva, constituindo espelhamento e articulando modos de vida; traz narrativas simples que se constituem basicamente sobre a luta entre o bem e o mal; funciona como espelho de uma consciência coletiva.

A partir deste ponto, vamos enveredar pelas searas de outro gênero importante na construção das histórias de ficção seriada que se filia ao melodrama, o folhetim.

\section{As marcas folhetinescas}

0 folhetim, do francês feuilleton (folha de livro), foi o primeiro gênero de massa da narrativa de ficção seriada escrita. $O$ folhetim começou a ser publicado nos jornais franceses em 1830 e ocupava a primeira página do jornal, como nota de rodapé. A princípio, eram publicados ao lado de notícias de variedades, geralmente associadas a fatos bizarros, piadas e até receitas culinárias. Em 1836, os jornais passam a funcionar comercialmente e a ter anúncios, que eram cobrados por palavras. Nessa época os jornais parisienses La Presse e Le Siècle dão início "à publicação de narrativas escritas por novelistas da moda" (MARTÍNBARBERO, 2009, p. 177). Tais narrativas, logo depois, começaram a ser publicadas no espaço que era do folhetim e, por isso, as histórias foram batizadas com esse nome ${ }^{7}$. Um folhetim que fez muito sucesso no final do século XIX e início do XX e depois teve desdobramento em

\footnotetext{
70 primeiro folhetim foi Lazarillo de Tornes, publicado em agosto de 1836, no jornal Le Siècle. Em outubro do mesmo ano, o jornal La Presse inicia a publicação de um texto de Honoré de Balzac como romance-folhetim. Mas considera-se que o primeiro romance-folhetim escrito para esse fim foi As memórias do diabo, de Frédéric Soulié, publicado em setembro de 1837 no jornal Journal des débats (MARTÍN-BARBERO, 2009).
} 
muitas adaptações, inclusive no cinema, foi a história do detetive inglês Sherlock Holmes, criada por Arthur Conan Doyle, originalmente publicada no jornal The Strand.

Uma intervenção tecnológica acompanhou um impacto social importante nesse período: a criação da rotativa; consequentemente os romances-folhetins puderam ser lidos pelo grande público, as massas que migravam para os centros urbanos, onde se concentravam as indústrias. 0 folhetim passou a servir como apelo de vendas e, ainda, se mostrou eficiente na fidelização do público.

Nas novelas - como narrativa literária publicada em uma única edição ou fragmentada nos jornais - podia-se perceber a presença de um elemento também presente no melodrama: a emoção. Ao referir-se às novelas, Lotman (2000) observa que esse gênero cria uma terceira pessoa (além da confluência do autor e do leitor no texto), que enriquece a aura emocional pela marcada expressividade de alguns elementos. 0 autor explica que, objetivamente, a novela se coloca fora do mundo do autor e do leitor, mas seu processo subjetivo coloca os dois dentro da trama e, dessa forma, a construção mais objetiva do texto não contradiz a subjetividade do leitor. Lotman adverte que na novela a mensagem se transfere do espaço dos nomes comuns para o espaço dos nomes próprios.

As histórias fragmentadas, contadas em capítulos, que assistimos hoje na televisão têm, portanto, a gênese do seu formato nos jornais do século XIX, com os folhetins. Mas não só. "Os formatos ficcionais da TV são herdeiros de um vasto caudal de formas narrativas e dramatúrgicas prévias: a narrativa oral, a literária, a radiofônica, a teatral, a pictórica, a fílmica e a mítica, entre outras." (BALOGH, 2002, p. 32). Porém, não cabe a esta reflexão destrinchar cada uma dessas heranças.

Cumpre desvelar apenas que o primeiro modelo de narrativa seriada audiovisual foi oferecido pelo cinema, por volta de 1913, quando surgem as primeiras experiências de serialização, posteriormente incorporadas pela televisão. A maioria das salas de cinema nessa época eram ainda os antigos nickelodeons, que exibiam filmes curtos - o público assistia em pé ou acomodado em bancos de madeira desconfortáveis. Os longas-metragens (feature films) exibidos nos salões de cinema eram pouco acessíveis ao grande público, mas podiam ser vistos por esse público na periferia, em partes, nos nickelodeons ${ }^{8}$. 0 que nos primórdios do cinema parecia certo amadorismo, com a televisão "[....] ganharia expressão industrial e forma significante [...]" (MACHADO, 2009, p. 87).

${ }^{8}$ São séries cinematográficas Fantômas (1913), de Louis Feuillade, e The perils of Pauline (1914), de Louis Garsnier (MACHADO, 2010). 
Por um lado, mostra-se a continuidade de certos traços do modo de contar histórias advindo do folhetim e, antes dele, da história oral, do circo, do teatro, da ópera. Por outro, as inovações tecnológicas permitem a mudança de suporte e, em decorrência disso, significativas adaptações e reconfigurações de códigos e linguagem. A memória vai se conservando, mas ao mesmo tempo se ajustando aos formatos e às criações que atravessam a dinâmica cultural.

É fato que razões intrínsecas à natureza televisual devem ser consideradas quando se pretende estudar as características de sua forma de contar histórias. Entre elas está uma audiência dispersa, e, assim, o enunciado televisual deve ser capaz de solicitar o telespectador para si. É uma forma de convocar o sujeito como já buscavam fazer o melodrama e o folhetim, mas que precisa ser pensada estrategicamente associada a outras táticas, apropriadas ao meio audiovisual. A necessidade de inserir anúncios publicitários no fluxo televisivo constituiu suas narrativas marcadamente pela fragmentação. No que se refere à ficção, a serialização se mostra como uma das suas principais formas de estruturação, o que implica conceber um padrão que se repete. Logo, "[...] chamamos de serialidade essa apresentação descontínua e fragmentada do sintagma televisual [...]." (MACHADO, 2009, p. 83, grifo no original).

Foi a serialização que impôs à televisão uma das suas principais técnicas narrativas: a existência de ganchos, herdada do gênero literário folhetim, que se perpetuou nas narrativas ficcionais televisuais. Os ganchos são informações impactantes que ficam sem respostas, as quais só serão dadas no próximo capítulo. Uma suspensão do sentido narrativo, capaz de segurar a tensão, que deve ser retomada na sequência do relato da história. A função do gancho narrativo é criar expectativa. "Trata-se de inventar um meio, mais ou menos nobre, de fazer com que o espectador volte a procurar o capítulo do dia seguinte - como, outrora, a dona de casa ia, em busca da sequência do folhetim, no jornal ou no fascículo." (PALLOTTINI, 2012, p. 103).

Assim sendo, não por mera coincidência, a telenovela é conhecida como folhetim eletrônico.

Lotman (1998) nos auxilia a pensar sobre esses arranjos da memória que ligam folhetim e teledramaturgia. Para o autor, os códigos da memória têm disposições específicas que, por vezes, correspondem a composições com base em épocas mais remotas e/ou em épocas mais recentes, ou mesmo em criação de novos códigos. Cabe ao pesquisador buscar os modos de deciframento mais adequados. 
[...] a constante atualização de diversos textos de épocas passadas, a constante presença de estados profundos e às vezes arcaicos da cultura no corte sincrônico desta, o diálogo da cultura do presente com várias estruturas e textos pertencentes ao passado, fazem duvidar que o evolucionismo trivial - segundo o qual há uma rigorosa linearidade de seu desenvolvimento e o passado da cultura se assemelha - seja o instrumento de investigação adequado [...]. (LOTMAN, 1998, p. 154, tradução nossa).

Na cultura vamos encontrar elementos constituidores de aspectos das narrativas de ficção seriada audiovisuais atuais que não estão organizadas numa linearidade cronológica. Personagens como vilões e heróis, já presentes nas narrativas orais, são resistentes ao tempo e se atualizam nas telenovelas em seus formatos mais hegemônicos. São textos separados por séculos que fazem conexão por meio da memória. Por outro lado, há marcas - como o poder de controle direto sobre o que pode ser manifestado - que se mostram com mais força em determinadas épocas e se apagam em outras. Um bom exemplo disso é a proibição de teatros populares na Inglaterra e na França no final do século XVII e início do século XIX, padrão que se repete na década de 1970 no Brasil com a proibição (pela censura da ditadura militar) da veiculação da novela Roque Santeiro.

\section{0 corte sincrônico: memória e criação}

0 gênero teledramaturgia se organiza a partir de formatos, os quais estão associados a lógicas de produção e usos (MARTíN-BARBERO, 2009), assim, pode-se dizer que, dentro do gênero televisual teledramaturgia, existem vários formatos.

Neste artigo nos deteremos mais na telenovela, caracterizada por ser uma narrativa de longa duração, cerca de 200 capítulos estruturados com ganchos narrativos. A telenovela apresenta núcleos dramáticos que comportam, além dos protagonistas, as personagens secundárias, e é uma obra aberta, que é produzida enquanto vai ao ar. Esse tipo de narrativa, geralmente, se estrutura a partir do tipo teleológico, que Machado (2009) atribui a narrativas que estabelecem logo no início da trama um conflito matriz, e toda a evolução dos acontecimentos visa reestabelecer o desequilíbrio instalado por esse conflito de base, às vezes, só resolvido nos capítulos finais.

Além da telenovela, as narrativas de ficção seriada na televisão também contam com outros formatos que resumimos a seguir. Os seriados são divididos em temporadas e distinguem-se dos demais formatos por terem episódios autônomos, enredos que se resolvem no mesmo dia em que são exibidos (PALLOTTINI, 2012). Os unitários são os programas especiais, que vão ao ar isoladamente, em finais de ano ou ocasiões comemorativas. A serialidade 
se dá por conta da narrativa fragmentada, na interrupção para a exibição dos intervalos comerciais. A minissérie é dividida em capítulos e não episódios, segundo Pallottini (2012). Naturalmente, o telespectador necessita da compreensão de todos os capítulos para que possa ter a totalidade da história.

Se no âmbito televisual a teledramaturgia é compreendida como gênero que contém diversos formatos, na Semiótica da Cultura é mais produtivo analisar as suas configurações por meio dos textos produzidos nesses âmbitos (sem desconsiderar gênero e formato). Os textos, afinal, estão impregnados de memória e, segundo Lotman (2003), podem ser vistos como um conjunto de signos em relação que produzem significados. Como apontamos acima, o texto televisual, entre outras especificidades, traz consigo características herdadas do melodrama e do folhetim em sua gênese, organizando-se pela sua característica mnemônica, mas não se pode esquecer da sua complexidade e seu caráter informativo e criativo, porque, como nos alerta o autor, “[...] a memória não é para a cultura um depósito passivo, se constitui parte de um mecanismo formador de textos." (LOTMAN, 1996, p. 111).

Entre os tantos aspectos possíveis de serem pinçados do eixo diacrônico para pensar a telenovela, especialmente a brasileira - e, pela sua significância no mercado, as produções da Rede Globo - é possível recuperar a presença de dialetos da memória (LOTMAN, 1996). Para o autor, os dialetos de memória se configuram a partir da organização interna dada por uma coletividade que, nesse caso, constituiria o mundo da telenovela. Esses dialetos fazem surgir semânticas locais, podem ser pensados como subestruturas culturais que assumem diferentes composições e volumes de memória, bem como diversos graus de elipticidade nos textos circundantes nas subcoletividades culturais. A telenovela brasileira, apesar da circulação global (exportação) e de temáticas que afetam diversos tipos de públicos, configurou um modo próprio de construção de narrativas e de organização de seus textos, tanto no que diz respeito ao formato, quanto no que tange às marcas narrativas. Nessa última perspectiva, o dialeto da telenovela brasileira se configura por meio da pergunta "Quem matou Odete Roitman?" (Vale Tudo), bem como pelas meias de lurex listradas e coloridas usadas com sandália por Julia Mattos (Dancing Days). Mas também se encontra no chacoalhar de pulso do sinhozinho Malta (Roque Santeiro) ou na explosão de dona Redonda (Saramandaia). Perguntas, usos, gestos como esses nem precisam de referência ao nome da novela, na verdade isso pouco importa, porque já estão incorporados ao dialeto da telenovela e, por consequência, à cultura midiática brasileira. 
Numa outra via, há as estruturas de maior abrangência, que remetem parcialmente aos traços do melodrama e do folhetim e que se constituem em categorias de composição textual que se repetem diacronicamente e que parecem sempre funcionar, por isso são reproduzidas. Por exemplo: toda telenovela tem um par romântico que enfrenta dificuldades e só fica junto no final da trama e, assim, toda novela tem que ter um casamento pelo menos. Contudo, outras tramas estruturantes repercutem: a luta do bem contra o mal; a pessoa que era pobre e ficou rica; o filho da empregada que (de início) é tratado como se fosse da família; a mocinha que tem vida sofrida, mas tem esperança e vive sorrindo.

Esse percurso nos faz defender que há uma linguagem clássica da teledramaturgia brasileira marcada pela memória, pelos modos de produção, pelos usos e apropriações, pelos vieses econômicos e políticos. Resumidamente, quando falamos na linguagem clássica/convencional das narrativas ficcionais na televisão, nos referimos ao modelo de representação da TV Globo, que privilegia, entre outros aspectos, a linearidade narrativa, o uso convencional dos planos de câmera (decupagem clássica), a serialização, as histórias padronizadas, geralmente com dois ou mais eixos dramáticos e com ganchos causais, muitas vezes previsíveis (MACHADO; 2009, 2011).

Contudo, não ignoramos que há uma função criativa do texto no momento em que os processos graduais da dinamicidade dos sistemas são atravessados pelas imprevisibilidades e, consequentemente, pela criação, conforme Lotman (2000). Mas isso é tema para outro artigo.

\section{Considerações finais}

Lotman (1996, p. 154) nos chama a atenção para o papel ordenador da memória na geração de novos textos, já que de tempos em tempos resgatamos da memória cultural coletiva determinado texto, por hora esquecido. Por isso, ele enfatiza: "A memória cultural como mecanismo criador não só é pancrônica, mas se opõe ao tempo. Conserva o passado, como algo que está [...]".

Nessa perspectiva, podemos pensar as telenovelas brasileiras como histórias de ficção seriada que variam pouco em sua constituição, segundo os moldes das narrativas ficcionais clássicas, porque, embora se reconfigurem diante das novas maneiras de se relacionar com a televisão na atualidade, mantêm características que falam diretamente a uma memória coletiva que faz jus a colocação de Martín-Barbero que enfatiza o melodrama como o "drama do reconhecimento" (2009, p. 306). 
Todavia, acreditamos que a teledramaturgia vive um momento de transformações intensas diante das questões impostas pela multiplicidade de formatos que vêm surgindo no audiovisual, em virtude do cenário da convergência midiática que, consequentemente, impõe mudanças nos modos de ver e produzir imagens na contemporaneidade. No entanto, seria ingênuo usar a expressão "não temos memória", pelo menos em se tratando de audiovisual, especialmente da ficção seriada. 0 desenvolvimento do artigo se pautou justamente por recuperar aspectos da teledramaturgia que se manifestam em sua diacronicidade.

Por isso, interessou sobremaneira a este artigo as premissas do gênero melodrama, visto como uma matriz cultural importante (MARTíN-BARBERO, 2009), para ser possível identificar e compreender quais as continuidades às características basilares de escrever histórias ficcionais para televisão que coexistem no que está sendo produzido e exibido na televisão - já que uma das principais vertentes contemporâneas do melodrama é, sem dúvida, a ficção televisual.

A pesquisa se concentrou ainda em apontar a herança dos folhetins, que garantiu a técnica dos ganchos narrativos, fundamentais na linguagem televisual. São os ganchos que suspendem o sentido da narrativa e "convidam" o telespectador a retomar a história no dia seguinte, mesmo que hoje sejam oferecidos serviços de canais de vídeos por demanda, como o Netflix, em que podemos assistir a temporada de uma série completa de uma única vez.

É possível perceber, portanto, que algumas continuidades às matrizes convencionais de se contar histórias de ficção seriada na televisão são mantidas, porque endossamos a concepção de Lotman (1996) que a memória coletiva é assegurada, em primeiro lugar, pela manutenção de alguns textos constantes e, em segundo, pelo seu caráter ininterrupto e regular de se transformar, o que é próprio da cultura que está em constante transformação.

Nesta via, é importante considerar que a cultura enquanto memória se reporta ao passado, está impregnada de historicidade, mas também funciona como um sistema modelizante de comportamentos e, por isso, visa o futuro (MACHADO, 2003).

\section{Referências}

BALOGH, Anna Maria. 0 discurso ficcional na TV: sedução e sonho em doses homeopáticas. São Paulo: Universidade de São Paulo, 2002.

BULHÕES, Marcelo. A ficção nas mídias: um curso sobre a narrativa nos meios audiovisuais. São Paulo: Ática, 2009.

BR0OKS, Peter. The melodramatic imagination. New Haven: Yale University, 1995. 
COCA, Adriana Pierre. As continuidades e as aproximações ao gênero melodrama na adaptação televisual de Dom Casmurro. Verso e Reverso, São Leopoldo, v. 28, p. 69-80, 2014. Disponível em:

<http://revistas.unisinos.br/index.php/versoereverso/article/viewFile/ver.2014.28.68.02/ 4183>. Acesso em: 1 fev. 2015.

IBOPE. TV aberta segue como meio de maior penetração na América Latina. Ibope, [S.l.], 22 ago. 2013. Disponível em: <http://www.ibope.com.br/pt-br/noticias/Paginas/TV-abertasegue-como-o-meio-de-maior-penetracao-na-America-Latina.aspx>. Acesso em: $30 \mathrm{abr}$. 2015.

LOPES, Maria Immacolata Vassallo de; OROZCO GÓMEZ, Guillermo (Coord.). Memória social e ficção televisiva em países ibero-americanos: anuário Obitel. Porto Alegre: Sulina, 2013. Disponível em: <http://obitel.net/wp-content/uploads/2015/07/obitel2013portugues.pdf>. Acesso em: 27 nov. 2015.

LOTMAN, Iuri. Cultura e explosão. Barcelona: Editorial Gedisa, 2000.

LOTMAN, Iuri. Sobre el concepto contemporâneo de texto. Entretextos, Granada, n. 2, nov. 2003.

LOTMAN, Iuri. Semiosfera I: semiótica de la cultura y del texto. Madrid: Cátedra, 1996.

LOTMAN, Iuri. La Semiosfera II: semiótica de la cultura, del texto, de la conducta y del espacio. Madrid: Ediciones Frónesis Cátedra Universitat de València, 1998.

MACHADO, Arlindo. A televisão levada a sério. 5. ed. São Paulo: Sena, 2009.

MACHADO, Arlindo. Pré-cinemas \& pós-cinemas. 6. ed. Campinas: Papirus, 2011.

MACHADO, Irene. Escola de semiótica: a experiência de Tártu-Moscou para o estudo da cultura. Cotia: Ateliê Editorial, 2003.

MARTÍN-BARBERO, Jesús. Dos meios às mediações: comunicação, cultura, hegemonia. 6 . ed. Rio de Janeiro: UFRJ, 2009.

MARTÍN-BARBERO, Jesús; REY, German. Os exercícios do ver: hegemonia audiovisual e ficção televisiva. São Paulo: Senac, 2001.

PALLOTTINI, Renata. Dramaturgia de televisão. 2. ed. São Paulo: Perspectiva, 2012.

THOMASSEAU, Jean-Marie. 0 melodrama. São Paulo: Perspectiva, 2005. 


\title{
Memory traces and the dynamics of creation in Brazilian television drama
}

\begin{abstract}
This study discusses the memory in television drama. Our main theoretical and methodological approach is based on the Semiotics of Culture in confluence with fictional narrative. We started from a survey of narrative techniques rooted in classical matrices for writing fictional stories for TV, especially the characteristics inherited from the melodrama and serials. This trajectory helps us understand the role of memory in cultural systems in the composition of serial fiction for television, particularly the telenovela, considering culture as a collective memory because it embodies the historicity of the systems of signs. We conclude that contemporary televisual fiction series are texts that bring out their own reconfiguration modes of producing and narrating in the digital communication era, constituting gradual and explosive processes; yet, these same narratives remain anchored in classical language.
\end{abstract}

\section{Keywords}

Television drama. Serial fiction. Memory. Semiotics of culture. Creation.

Recebido em 21/09/2015

Aceito em 03/12/2015 